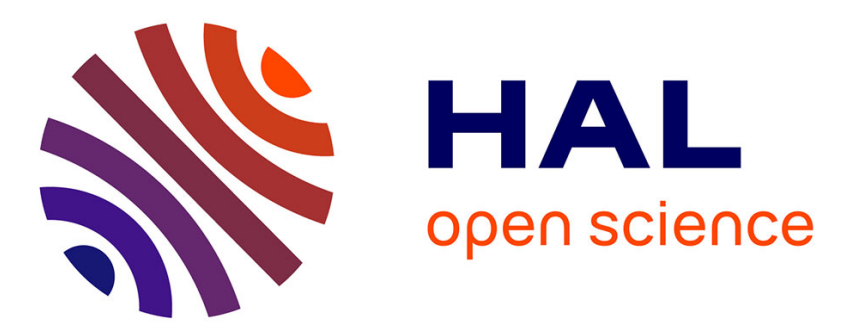

\title{
Spray cast Al-Si base alloys for stiffness and fatigue strength requirements
}

\author{
M. Courbiere, A. Mocellin
}

\section{To cite this version:}

M. Courbiere, A. Mocellin. Spray cast Al-Si base alloys for stiffness and fatigue strength requirements. Journal de Physique IV Proceedings, 1993, 03 (C7), pp.C7-207-C7-213. 10.1051/jp4:1993731 . jpa00251954

\section{HAL Id: jpa-00251954 https://hal.science/jpa-00251954}

Submitted on 1 Jan 1993

HAL is a multi-disciplinary open access archive for the deposit and dissemination of scientific research documents, whether they are published or not. The documents may come from teaching and research institutions in France or abroad, or from public or private research centers.
L'archive ouverte pluridisciplinaire HAL, est destinée au dépôt et à la diffusion de documents scientifiques de niveau recherche, publiés ou non, émanant des établissements d'enseignement et de recherche français ou étrangers, des laboratoires publics ou privés. 


\title{
Spray cast Al-Si base alloys for stiffness and fatigue strength requirements
}

\author{
M. COURBIERE and A. MOCELLIN* \\ Pechiney, Centre de Recherches de Voreppe, France \\ * INSA Lyon, Laboratoire GEMPPM
}

\section{SUMMARY}

Hypereutectic AlSiFe spray-cast alloys exhibit properties similar to those of metal-matrix composite (MMC's) : high Young's modulus and a low coefficient of thermal expansion. These physical properties can be adjusted by changing the Si content of the alloy.

The refinement of the microstructure is produced by formation of a large amount of nuclei in the spray. Consolidation done by extrusion (bars, tubes or profiles) and/or forging leads to high mechanical properties, especially very good dynamic properties.

High fatigue properties coupled with high modulus, good high temperature behaviour and low thermal expansion, allow their use for applications in the automotive industry.

In opposition to MMC's, these materials present the advantage of easy recycling and easy machinability as it is the case for the conventional AlSi alloys.

The low oxygen content allows quality joining with conventional arc welding techniques.

\section{INTRODUCTION}

In spite of advantageous properties such as low density and high casting properties, the aluminiumsilicon alloys, as other aluminium series alloys $(2 \mathrm{xxx}, 7 \mathrm{xxx})$, present rather low Young modulus, low fatigue resistance and poor behaviour at high temperature in comparison with steels or cast irons.

The way of improvement would consist in increasing the amount of elements of addition such as silicon, iron or nickel. Unfortunately it is not possible because it leads to the formation of coarse intermetallic phases which decrease drastically the resistance of the material especially for hypereutectic compositions. Addition of elements which modify the size and the shape of silicon have been used in conventional moulding [1] and casting but they can only enhance a little the level of mechanical properties.

It is well known that grain size, dendrite arm spacing (DAS) and sizes of intermetallic particles are correlated with the cooling rate during solidification [2]. Several technologies can be used to avoid particle coarsening during the high cooling rate [3] :

- splat cooling technique, based on quenching of molten metal onto a cold metallic surface,

- melt spinning technique which is based on cooling during the flight in the gas atmosphere of a chamber or atomization with gas at high pressure which produces finer particles. The alloys are melt-spun into ribbons or powders which are canned and consolidated by extrusion or die forging [4][5].

In the early 60 's spray forming technologies have been developed on the base of the two technologies mentioned [6] ; they allow to produce semi-products with only one operation. Unfortunately the thickness of the deposit was limited by the loss of cooling efficiency of the collector. Based on these 
works, OSPREY Metals Ltd has developed in the 70's a similar process which allows the fabrication of similar alloys without the disadvantage mentioned previously. The process is known as OSPREY process [7].

\section{COMPOSITIONS, ELABORATION OF MATERIALS AND BASIC PROPERTIES}

As the OSPREY process includes an atomization step, it permits refinement of the microstructure. It allows the addition of large amounts of elements (silicon, iron) [4] which can not be added by conventional casting technologies due to the coarsening of the intermetallic phases. These elements with or without combination with aluminium can lead to high volume fractions of intermetallic particles at the level of ceramic reinforcement in metal matrix composites (MMC's). The alloys studied here [8] contain $2 \%$ of copper and $0.5 \%$ of magnesium to allow precipitation hardening; $0.8 \%$ of manganese and $0.2 \%$ of zirconium have been added to these compositions in order to improve the fatigue behaviour. High chemical homogeneity is achieved with low oxygen content in comparison with powder metallurgy products. Table 1 presents the oxygen content measured by neutron-activation technique.

\begin{tabular}{|c|c|}
\hline Material & \% oxygen \\
\hline 4032 AlSi12CuNi (DC casting) & $5 \mathrm{ppm}$ \\
\hline $\mathrm{AlSi} 15 \mathrm{Fe} 3$ (PM) & $1200 \mathrm{ppm}$ \\
\hline $\mathrm{AlSi15Fe}$ (OSPREY) & $140 \mathrm{ppm}$ \\
\hline $2014+15 \% \mathrm{Al}_{2} \mathrm{O}_{3}$ (Squeeze casting) & $800 \mathrm{ppm}$ \\
\hline
\end{tabular}

Table 1: Oxygen content of materials elaborated by different routes

High silicon content alloys (up to $25 \%$ ) containing $3 \%$ iron have been spray-cast at a temperature $100^{\circ} \mathrm{C}$ over the liquidus of the alloys. The liquid metal has been cooled by an impingement of nitrogen using a metal-gas ratio flow rate included between 3.5 and $4.5 \mathrm{Nm}^{3} / \mathrm{kg}$. The preforms containing between 3 and $5 \%$ porosity have been extruded to obtain bars with an extrusion ratio of 12.8 . These alloys can be easily extruded up to $25 \%$ of silicon. The bars have been heat treated with T6 treatment to obtain maximum resistance.

We have mentioned in reference the characteristics obtained with alumina reinforced materials (2014 + $15 \% \mathrm{Al}_{2} \mathrm{O}_{3}$ ) obtained by squeeze casting and 4032 alloys obtained by conventional semi continuous casting.

The small amount of oxygen, in comparison with powder metallurgy and with metal matrix composite (MMC's), allows a good weldability of the material. This oxygen concentration has also a strong impact on the recycling of materials which is possible with OSPREY AlSiFe materials and not with MMC's.

As for conventional mould AlSi alloys the machinability is excellent and avoid strong wear of machining tools as it is unfortunately observed with MMC's.

\section{MICROSTUCTURE}

The alloys exhibit a fine composite microstructure [13] due to the hypereutectic compositions in as-cast preforms. They do not present coarse primary phases due to the high solidification rate in the spray and to cooling down in a mushy zone on the top of the preform. The microstructure as observed with optical microscope is composed of fine silicon particles (appearing grey on micrographs) and of smaller AlSiFe intermetallic particles (appearing white) (Fig. 1).The copper and magnesium eutectic phase is not clearly visible. The grains have a size of 0,5 to $3 \mu \mathrm{m}$ and are equiaxed on as-sprayed materials. Some pores are present in the as-sprayed preforms.

Transmission electron microscopy on T6 heat treated materials shows that the shape of the intermetallic 
AlSiFe phases is affected by the presence of manganese. Manganese favour the presence of spherical precipitates ( $\mathrm{Al}, \mathrm{Si}, \mathrm{Fe}, \mathrm{Mn}$ ) which are cubic structure with lattice parameter a $=1.267 \mathrm{~nm}$ [9]. Free manganese phases $\beta$ ( $\mathrm{Al}, \mathrm{Fe}, \mathrm{Si}$ ) exhibit elongated shape (aspect ratio of 2 to 8 ). Their crystallographic structure has been identified by electron diffraction to be monoclinic with parameters $a=b=0.64 \mathrm{~nm}$, $c=4,26 \mathrm{~nm}, \alpha=\gamma=90^{\circ}$ and $\beta=91^{\circ}$ slightly different from those known [10].

The matrix exhibits similar phases as $2 \mathrm{xxx}$ series alloys ; the microstructure presents the three structural hardening phases $S^{\prime}(\mathrm{Al} 2 \mathrm{CuMg}), \lambda^{\prime}(\mathrm{Al} 5 \mathrm{Cu} 2 \mathrm{Mg} 8 \mathrm{Si} 7)$ and $\theta^{\prime}(\mathrm{Al} 2 \mathrm{Cu})$. Precipitate free zones are present at some grain boundaries with a size of the range of $50 \mathrm{~nm}$.

\section{PHYSICAL ET MECHANICAL PROPERTIES}

The addition of ceramic particles such as $\mathrm{Al}_{2} \mathrm{O}_{3}, \mathrm{SiC} \ldots$ is well known to increase the Young's modulus of aluminium alloys. This effect is used in elaboration of MMC's. With aluminium-silicon-iron systems, these particles are the primary phases ( $\mathrm{Si}$ and $\mathrm{AlSiFe}$ ) obtained in situ during the solidification ; they have the same effect on the enhancement of the modulus as the ceramic particles added in MMC's. These intermetallic phases present features which are favourable to the coefficient of thermal expansion of the materials which can be lower than $20.10^{-6} / \mathrm{K}$ (Fig. 2). The total volume fraction of intermetallic phases is about $30 \%$ with the $15 \%$ silicon content.

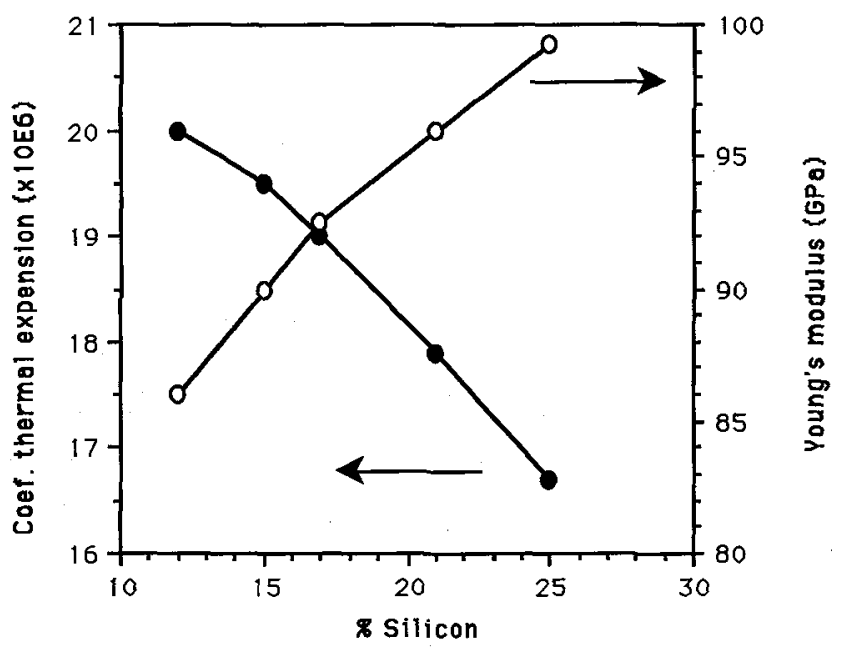

Fig. 2 : Evolution of physical properties with silicon content

A significant improvement of the resistance is obtained in comparison with conventional 4032 aluminum alloy obtained by DC casting and extrusion. This improvement is linked to loss of elongation when silicon content increases. These alloys present a rather good behaviour after holding at very high temperature. 


\begin{tabular}{|c|c|c|c|c|c|c|c|}
\hline & 4032 & AlSi12Fe3 & AlSi15Fe3 & AlSi17Fe3 & AlSi21Fe3 & AlSi25Fe3 & $\begin{array}{c}2014+ \\
15 \% \\
\mathrm{Al}_{2} \mathrm{O}_{3}\end{array}$ \\
\hline at 20 C & & & & & & & \\
Y.S.(MPa) & 350 & 392 & 415 & 400 & 410 & 440 & 462 \\
U.T.S. (MPa) & 402 & 463 & 475 & 470 & 473 & 503 & 497 \\
A \% & 5.5 & 4.7 & 2 & 1.3 & 0.8 & 0.6 & 1.7 \\
\hline after 100 h at 350 C & & & & & & & \\
Y.S. (MPa) & 31 & & 55 & 64 & 72 & 80 & 41 \\
U.T.S. (MPa) & 44 & & 59 & 73 & 83 & 97 & 43 \\
A \% & 60 & & 43 & 24 & 15 & 12 & 20 \\
\hline
\end{tabular}

Table 2 : Properties under static loading obtained on extrusion

The OSPREY alloys exhibit a much better behaviour under dynamic loading than conventional 4032 (Table 3). This good level of fatigue properties is also observed on notched samples. In spite of the decrease of the fatigue limit after holding $1000 \mathrm{~h}$ at $150^{\circ} \mathrm{C}$ the level is still higher than the composite tested. Fatigue tests performed in tensile-compression mode $(R=-1)$ on the 15,21 and $25 \%$ silicon content show an obvious gain in comparison with others materials. It is important to mention that the endurance ratio Fatigue limit/ U.T.S. is much higher with OSPREY materials than with conventional 4032 or composite material.

The influence of silicon content is not significant on the smooth specimens as well with flexion test as with tensile-compression test. The real improvement of silicon-content increasing is shown on notched specimens where the crack is located at a precise area of the specimen.

\begin{tabular}{|c|c|c|c|c|c|}
\hline \multirow{3}{*}{ Alloys } & \multicolumn{3}{|c|}{ Rotative-bending test } & Trac./Comp & fatigue limit/ \\
\hline & on T6 hea & treatment & after aging & at $150^{\circ} \mathrm{C}$ & U.T.S. \\
\hline & $\mathrm{Kt}=1$ & $\mathrm{Kt}=2.2$ & $1000 \mathrm{~h}$ at $150^{\circ} \mathrm{C}$ & $R=-1$ & $\mathrm{Kt}=1$ \\
\hline 4032 (AlSi12CuNi) & 129 & 83 & 123 & 118 & 0.32 \\
\hline AlSi12Fe3 & 200 & 118 & & & 0.43 \\
\hline AlSi15Fe3 & 195 & 123 & 178 & 162 & 0.41 \\
\hline $\mathrm{AlSi} 21 \mathrm{Fe} 3$ & 180 & 135 & 160 & 160 & 0.38 \\
\hline AlSi25Fe 3 & 200 & 150 & 165 & 165 & 0.40 \\
\hline $2014+15 \% \mathrm{Al}_{2} \mathrm{O}_{3}$ & 150 & 127 & 150 & 110 & 0.30 \\
\hline
\end{tabular}

Table 3 : Fatigue limit properties at $10^{7}$ cycles (log-average value)

\section{MICROSTRUCTURAL INVESTIGATIONS OF CRACK PROPAGATION}

It has been observed that very often the origin of specimens failure, under tensile test and cyclic loading, is due to some flows such as microporosities, larger silicon or intermetallic phase. The micromechanisms of damage have been established thanks to in situ scanning electron microscope investigation using gold microgrids to visualize local microstrains and microcracks [11].

They can be described and summarized as follows [11] [13]. Plastic deformation of the matrix begins near the silicon particles and becomes visible on the grids at $1 \%$ of macroscopic plastic strain. Silicon particles progressively crack with increasing plastic strain. Cracking takes place perpendicularly to the tensile axis and the largest particles are first concerned (Fig. 3). Then particle cracks open, taking a 
rectangular shape, and give local stress concentrations at their tips; they are released by grain boundaries shearing. The shearing bands tend to join together and the failure of the sample involves intergranular decohesions between cracked silicon particles (Fig. 4).

The damage stage by particles cracking can be characterized in several ways in order to correlate the plastic strain to the volume fraction of cracked particles. Recording of acoustic emission signals shows qualitatively how the number of acoustic events increases rapidly from the beginning of particles crackings to the fracture of the sample. To quantify the phenomenon, the values of elastic modulus, measured at the growing states of plastic strain, have been used.

These microstructural mechanisms of damage are almost the same in the case of cyclic loading. The main difference comes from the propagation mode of microcracks which involves a quasi-ductile aspect (Fig. 5). Development and coalescence of fatigue microcracks seem to control the major part of the fatigue life. The existence of such steps of slow and jerky propagation of a multitude of microcracks surely contributes to improve the fatigue resistance of AlSiFe elaborated by the OSPREY route.

\section{DISCUSSION}

The new AISiFe alloys, obtained by the OSPREY route, present a microstructure and a mechanical behaviour like those of composite materials. The great amount of silicon and intermetallic phases in these alloys plays the role of reinforcing particles like in MMC's [14] and has the same effect on fatigue and temperature behaviour. Their high modulus takes certainly an important role [15]. Moreover small grain size has to be noticed.

This type of microstructure is responsible for the observed mechanical properties.

The high elastic modulus value is linked to the presence of a great volume fraction of phases with elastic moduli much higher than those of the matrix [11].

The high fatigue resistance can be explained from the following considerations :

- the high elastic limit of the matrix, due to the effect of small grain size, intermetallic phases and intergranular precipitation, limits considerably the plastic strain which tends to accumulate near silicon particles; the fracture nucleation is thus delayed,

- the difference of thermal expansion coefficients between aluminium and silicon leads to compressive internal stress fields in silicon particles. The compression level seems to depend on the morphology of intermetallic particles and is more elevated with spherical ones [11].

- microcrack propagation, at grain boundaries and at interfaces between matrix and intermetallic phases, is slowed down by the great number of grains (small size) and a lot of intermetallic particles of different types and sizes. The microcrack paths are thus longer and the junction between them takes a greater part in the fatigue life. In spite of a good behaviour in regard to the crack propagation, it seems important to avoid defects larger than the size of silicon which are often at the origin of first initiation of cracks in these materials.

\section{CONCLUSION}

Spray deposited AlSiFe alloys are very promising for applications requiring high fatigue behaviour and/or high modulus. They present especially good resistance to damage at engine temperatures which allow their use in parts such as connecting rods or pistons.

These properties are due to the presence of refined silicon and AlSi (Fe, Mn) particles which slow down the cracks propagation and the crack path. This effect is explained by the stress field induced into the aluminium matrix by these particles and by the small grain size. 


\section{BIBLIOGRAPHY}

[1] R.A. Legge, D.M. Smith, G. Henkel

Proceeding of International Congress \& Exposition. Detroit (1986)

[2] S. Inumaru, S. Yamauchi, H.Sano.

Sumitomo light metals Tech. report (1984) 25 (3) p.50-60

[3] M.J. Fleetwood

Metals \& Materials, january 1987 p.14-20

[4] F. Hehmann, Y. Bienvenu, M. Durand, B. Munar, U. Eilrich, K. Hummert, P. Lasne, C. Levaillant.

Proceeding of PM90 (London), The Institute of Metals, (1990) Vol. 1, pp 216-225

[5] H.T. Shin, M. Suganuma, J. Kaneko.

Kei Kinzoku Vol. $42, \mathrm{~N}^{\circ} 1$ pp. 38-44

[6] R.F. Singer

Metal Technology. February 1983) vol.10 p.61

[7] A. Leatham, A. Ogilvy, P. Chesney, J.V. Wood

Metals and Materials, march 1989, pp 140-143

[8] Patent n'US 4923 676, EP 320417 and US 4992 242, US 4963 322, EP 362086.

[9] M. Cooper, K. Robinson.

Acta Crystallographica, 1966, vol.20, part 5, p. 614-619

[10] M. Yang, V.D. Scott.

Journal of Materials Science, 1991, vol.26, n8, p.2245-2254

[11] A. Mocellin.

Thèse de doctorat, INSA de Lyon, 1993, 258 pages nº d'ordre 93 ISAL 0008

[12] A. Mocellin, R. Fougères, P.F. Gobin. Accepted for publication in Journal of Materials Science

(February 1993)

[13] J. Ziiou, J. Duskzczyk, B.M. Korevaar.

Journal of Materials Science, 1991 vol. $26 \mathrm{n}^{\circ} 9$ p.5275-5291

[14] J.C. Healy.

Materials Sciences and Engineering A, 1991, vol A142, n² p.183-192

[15] J.J Bonnen, J.E. Allison, J.W. Jones.

Metallurgical Transactions A, 1991, vol. 22A, n5, p. 1007-1019 


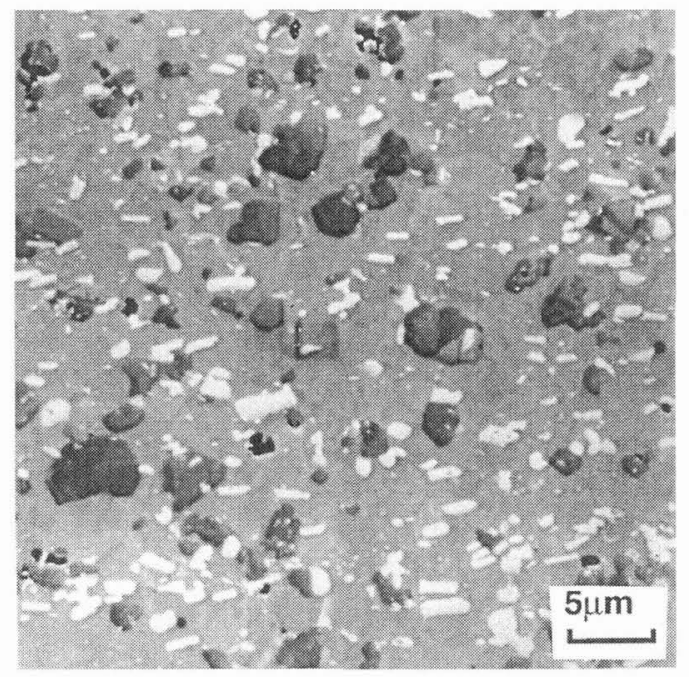

Fig. I : SEM picture of AlSi15Fe3

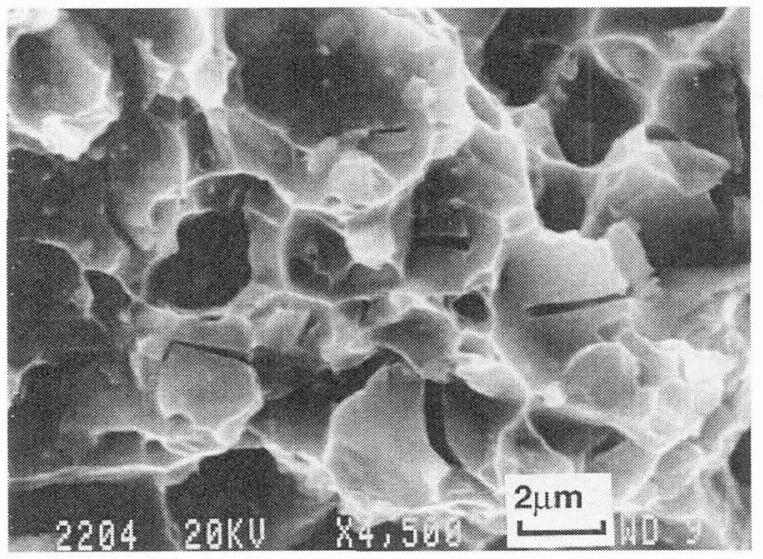

Fig. 3: Fracture surface observed on tensile test specimen

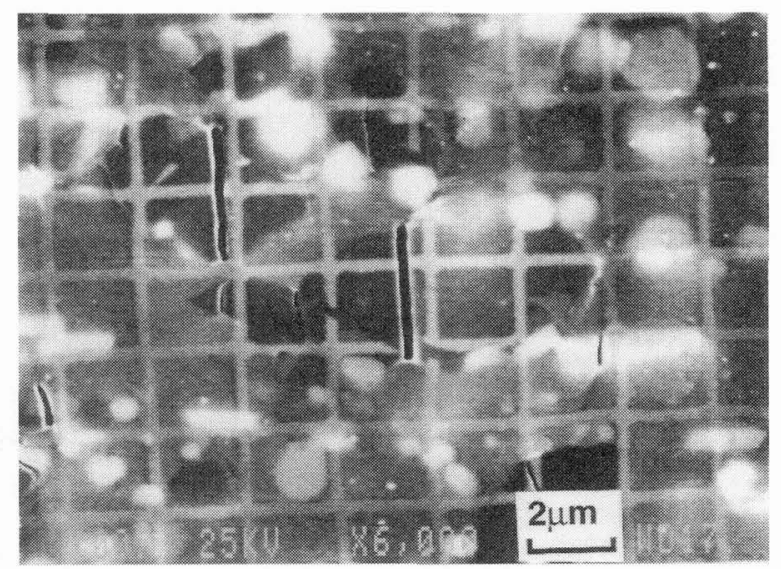

Fig. 2 : Initiation of cracks in Silicon particles

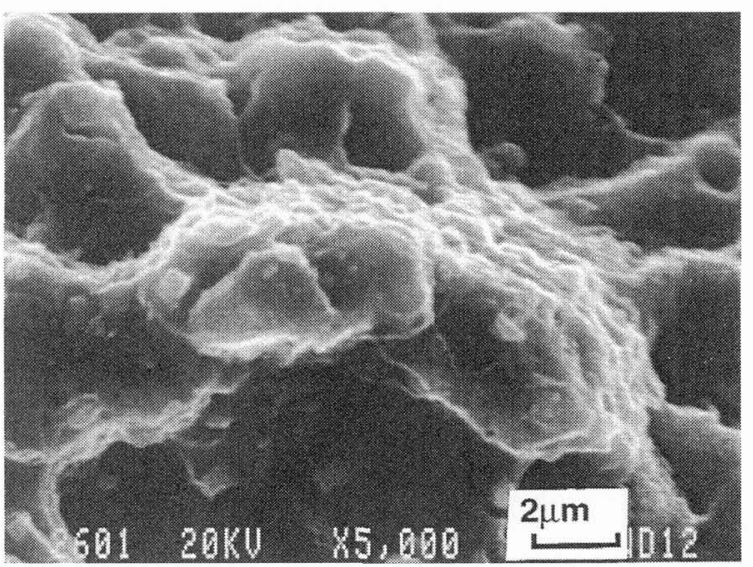

Fig. 4: Fracture surface observed on fatigue test specimen 